\title{
KAJIAN ERODIBILITAS TANAH PADA BEBERAPA SUB GROUP TANAH DI KECAMATAN SEMIN
}

\section{(STUDY OF SOIL ERODIBILITY AT VARIOUS SOIL SUB GROUPS IN SEMIN SUB-DISTRICT)}

\author{
Dwi Kurnia Sandi ${ }^{1}$, Djoko Mulyanto ${ }^{2 *}$, dan Dyah Arbiwati ${ }^{2)}$ \\ 1) Prodi Agroteknologi, Universitas Pembangunan Nasional Veteran Yogyakarta \\ 2) Prodi Ilmu Tanah, Universitas Pembangunan Nasional Veteran Yogyakarta \\ ${ }^{*}$ Corresponding author E - mail: j.mulyanto@upnyk.ac.id
}

\begin{abstract}
Soil loss triggered by water erosion is a major problem causing several environmental problems. Soil erosion contributes to loss of fertility and decreasing of the quality of soil resources. One of the components that plays an important role in the process of soil erosion is soil erodibility, namely the sensitivity of the soil to erosion.The sub-district of Semin has 4 sub-groups of soil, namely Typic Hapluderts, Typic Eutropepts, Typic Troporthents and Lithic Haplustols. The four soil sub-groups have different characteristics. The purpose of this study was to interpret the erodibility value of each sub-group of land in Semin District. This study used a survey method, sampling based on the map of land units of the Semin district. Observation of soil structure and taking soil samples by a mini pit and using a ring sampler. Soil erodibility data analysis was carried out using the 1978 Weischmeier equation, namely $100 \mathrm{~K}=1.292$ [2,1 M1,14 (10-4) (12a) $+3,25(b-2)+2,5(c-3)]$. The results showed that the highest erodibility value at the Typic Hapluderts sub-group, namely 0.730 (very high erodibility class), it was located on a gentle slope, while the lowest erodibility value at the Typic Hapluderts sub-group, namely 0.184 (low erodibility class) located at a slightly steep slope. The order of magnitude of erodibility values on relatively similar slopes is: Typic Troporthents> Lithic Haplustols> Typic Eutropepts> Typic Hapluderts. In general, the higher the slope of the same sub group, the erodibility value increases. The factors that determine the soil erodibility value are organic matter and soil texture, especially the clay fraction, dust and very fine sand.
\end{abstract}

Keywords: erodibility, Semin Sub-District, soil sub groups

\begin{abstract}
ABSTRAK
Kehilangan tanah yang dipicu oleh erosi air merupakan masalah utama yang menyebabkan beberapa masalah lingkungan. Erosi tanah berkontribusi pada hilangnya kesuburan dan penurunan kualitas sumber daya tanah. Salah satu komponen yang berperan penting dalam proses erosi tanah adalah erodibilitas tanah, yakni kepekaan tanah terhadap erosi. Wilayah Kecamatan Semin memiliki 4 sub group tanah yaitu Typic Hapluderts, Typic Eutropepts, Typic Troporthents dan Lithic Haplustols. Keempat sub group tanah tersebut memiliki sifat-sifat yang berbeda. Tujuan dari penelitian ini untuk mengetahui nilai erodibilitas pada setiap sub group tanah yang terdapat di Kecamatan Semin. Penelitian ini menggunakan Metode Survey, pengambilan sampel tanah secara Purposive berdasarkan Peta Satuan Lahan Kecamatan Semin. Pengamatan struktur tanah dan pengambilan sampel tanah yang akan dianalisis dilakukan
\end{abstract}


dengan cara membuat mini pit dan menggunakan ring sampler. Analisis data erodibilitas tanah dilakukan dengan menggunakan persamaan Weischmeier 1978 yaitu $100 \mathrm{~K}=1,292$ [2,1 M1,14 $(10-4)(12-a)+3,25(b-2)+2,5(c-3)]$. Hasil Penelitian menunjukkan bahwa nilai erodibilitas tertinggi pada sub group tanah Typic Troporthents yakni 0,730 dengan kisaran sangat tinggi yang terletak pada kemiringan lereng landai, sedangkan nilai erodibilitas terendah pada sub group Typic Hapluderts yaitu 0,184 dengan status rendah pada kemiringan lereng agak curam. Secara umum urutan besarnya nilai erodibilitas pada lereng yang relatif sama adalah: Typic Troporthents > Lithic Haplustols > Typic Eutropepts > Typic Hapluderts. Secara umum semakin tinggi kelerengan pada sub grup yang sama, erodibilitasnya semakin meningkat. Faktor yang menentukan nilai erodibilitas tanah adalah bahan organik dan tekstur tanah khususnya fraksi lempung, debu dan pasir sangat halus.

Kata kunci : erodibilitas, Kecamatan Semin, sub group tanah

\section{PENDAHULUAN}

Pengetahuan tentang erodibilitas tanah merupakan persyaratan penting untuk memprediksi erosi, perencanaan konservasi, dan penafsiran pengaruh lingkungan terkait sedimen dari kegiatan pertanian di suatu DAS (B. Wang et al.,.., 2013). Erodibilitas tanah biasanya dianggap sebagai kerentanan tanah untuk terkikis. Dalam pengertian mendasar, seharusnya didefinisikan sebagai jumlah kehilangan tanah per unit gaya eksogenik atau erosivitas curah hujan, aliran permukaan, dan rembesan.(Dusan, 1982; Bryan et al.,., 1989). Bentuk permukaan bumi selalu mengalami perubahan yang banyak dipengaruhi oleh proses geomorfik, salah satunya melalui proses erosi. Studi erosi sangat penting baik dalam bidang pertanian, maupun kehutanan karena dengan mengetahui tingkat erosi yang ada di suatu daerah maka dapat mengambil langkahlangkah dalam mengantisipasi tingkat erosi lebih lanjut, yaitu dengan konservasi tanah baik secara mekanik, vegetatif, maupun kimia agar kelestarian tanah dan produktivitas tanah tetap terjaga. Banyak faktor yang terkait dengan erosi tanah,yakni erosivitas hujan, erodibilitas tanah, panjang dan kemiringan lereng, vegetasi dan manusia. Dari keenam faktor tersebut salah satu faktor penyebab ketahanan terhadap erosi tanah adalah erodibilitas tanah.

Berdasarkan data Pusat Penelitian Tanah dan Agroklimat Bogor (2001), Kecamatan Semin memiliki 4 sub group tanah yaitu Typic Troporthents, Typic Eutropepts, Typic Hapluderts dan Lithic Haplustols. Berdasarkan Soil Survey Staff (2014), keempat sub group tanah tersebut memiliki karakteristik yang berbeda-beda sehingga dapat mempengaruhi nilai erodibilitas tanah. Hal ini yang menyebabkan peneliti melakukan kajian terhadap nilai erodibilitas tanah pada 4 sub group tanah yang terdapat di Kecamatan Semin.

\section{BAHAN DAN METODE}

Penelitian telah dilaksanakan di Kecamatan Semin, Gunungkidul, Daerah Istimewa Yogyakarta. Bahan yang digunakan dalam penelitian diantaranya yaitu sampel tanah, kemikalia, data peta sub group tanah. Alat yang digunakan alat tulis, pisau, meteran, cangkul, ring sampler, tabung sedimentasi, permeameter, labu takar, ayakan tanah. Penelitian ini dilaksanakan dengan menggunakan metode Survey, penentuan titik 
sampel tanah ditentukan secara random pada tiap satuan lahan yang diperoleh berdasarkan overlay Peta Sub Group Tanah, Peta Penggunaan Lahan, dan Peta Kemiringan Lereng sehingga diperoleh 12 Satuan Peta Lahan dengan jumlah total titik pengambilan sampel sebanyak 12 titik. Pengambilan sampel tanah dilakukan dengan pembuatan mini pid dan ring sampler untuk pengamatan permeabilitas tanah. Pada Penelitian ini ada 4 parameter yang diamati yaitu struktur tanah, tekstur tanah, permeabilitas tanah dan C-Organik. Pengukuran tekstur tanah menggunakan metode Pipet, pengukuran struktur tanah menggunakan metode Slidik Cepat di lapangan, permeabilitas menggunakan metode Hukum Darcy dan C-Organik menggunakan metode Walkley and Black. Analisis data erodibilitas tanah menggunakan persamaan (Weischmeier, et al.,1, 1978) yaitu $100 \mathrm{~K}=1,292$ [2,1 M1,14 (10-4) (12-a) + 3,25 (b-2) $+2,5$ (c-3)] dengan keterangan M: ukuran partikel (\% pasir sangat halus+ \% debu) (100-\% lempung), a: kandungan bahan organik (\% $\mathrm{C}$ 1,724), b: harkat struktur tanah dan c: harkat permeabilitas tanah.

\section{HASIL DAN PEMBAHASAN}

Hasil Penelitian yang telah dilakukan di Kecamatan Semin diperoleh data perhitungan nilai erodibilitas dengan menggunakan persamaan Weischmeier (1978), $100 \mathrm{~K}=1,292$ [2,1 M1,14 (10-4)(12-a) + 3,25(b-2) + 2,5(c-3)] yang akan disajikan pada Tabel 1 dan kelas erodibilitas akan disajikan pada Gambar 1. Perhitungan nilai $\mathrm{K}$ pada Satuan peta Lahan Typic Hapluderts Datar :

$100 \mathrm{~K}=1,292[2,1 \times 11521,14(104)(12-2,10)+3,25(4-2)+2,5(5-3)]$

$100 \mathrm{~K}=2,713 \times 3090,6 \times 0.0001 \times 9,9+6,5+5$

$100 \mathrm{~K}=8,300+6,5+5$

$\mathrm{K}=19,800 / 100$

$\mathrm{K}=0,198$

Pada sub group tanah yang sama dan kemiringan lereng berbeda diketahui bahwa nilai K tertinggi pada sub group tanah Typic Hapluderts Datar. Hal ini dipengaruhi oleh $\%$ lempung yang lebih sedikit dibandingkan Typic Hapluderts Landai dan Typic Hapluderts Agak curam, namun dari ketiga kemiringan lereng yang berbeda memiliki nilai K yang masih dalam satu harkat erodibilitas yang sama yaitu rendah. Menurut Wischmeier dan Smith (1978), persentase pasir, debu dan lempung halus dianggap mempunyai hubungan yang erat terhadap sifat fisik kimia tanah pada lapisan permukaan. Apabila rasio pasir terhadap debu berkurang, maka nilai kepekaan erosi menjadi bertambah besar. Hal tersebut bolehjadi terkait juga dengan kemantapan agregat, yang mana penambahan persen lempung mempengaruhi daya ikat dengan bahan organik yang cenderung meningkatkan agregasi butir-butir tanah. Keterkaitan antara kemantapan agregat dengan erodibilitas telah disampaikan oleh De Ploey dan Poesen, 1985 bahwa Kerentanan tanah terhadap erosi, atau erodibilitas tanah, saling terkait dengan stabilitas agregat tanah.

Pada sub group tanah yang sama dan kemiringan lereng berbeda diketahui bahwa nilai $\mathrm{K}$ tertinggi pada sub group tanah Typic Eutropepts dengan kemiringan lereng agak curam, kemudian diikuti dengan kemiringan lereng landai dan yang terendah pada kemiringan lereng datar. Hal ini dikarenakan pada sub group tanah Typic Eutropepts 
dengan kemiringan lereng agak curam, memiliki perbandingan antara fraksi debu dan pasir sangat halus dengan lempung tidak jauh berbeda serta kandungan bahan organik yang rendah sehingga agregat tanah atau ikatan antar partikel tanah yang tidak terlalu kuat, serta semakin curam kemiringan lereng maka aliran air permukaan semakin cepat yang menyebabkan kesempatan air untuk terserap ke dalam tanah atau infiltrasi lebih lambat dibandingkan dengan laju air permukaan.

Tabel 1. Erodibilitas Tanah di Keceamatan Semin Kabupaten Gunung Kidul

\begin{tabular}{|c|c|c|c|c|c|c|c|c|}
\hline No & Sub Group Tanah & Kode & $\mathbf{M}$ & $\begin{array}{c}\text { BO } \\
\%\end{array}$ & $\begin{array}{c}\text { Harkat } \\
\text { Struktur }\end{array}$ & $\begin{array}{c}\text { Harkat } \\
\text { Pmb }\end{array}$ & $\mathbf{K}$ & Kelas \\
\hline 1 & Typic Hapluderts & TH-D & 1152 & 2,10 & 4 & 5 & 0,198 & rendah \\
\hline 2 & Typic Hapluderts & TH-L & 1002 & 1,27 & 4 & 5 & 0,192 & rendah \\
\hline 3 & Typic Hapluderts & $\begin{array}{l}\mathrm{TH}- \\
\mathrm{AC}\end{array}$ & 934 & 1,5 & 4 & 5 & 0,184 & rendah \\
\hline 4 & Typic Eutropepts & TE-D & 1218 & 1,17 & 4 & 5 & 0,212 & rendah \\
\hline 5 & Typic Eutropepts & TE-L & 1622 & 1,65 & 4 & 5 & 0,243 & sedang \\
\hline 6 & Typic Eutropepts & $\begin{array}{l}\text { TE- } \\
\text { AC }\end{array}$ & 1863 & 1,49 & 4 & 5 & 0,267 & sedang \\
\hline 7 & $\begin{array}{l}\text { Typic } \\
\text { Troporthents }\end{array}$ & TT-D & 2690 & 0,84 & 4 & 5 & 0,361 & agak tingg \\
\hline 8 & $\begin{array}{l}\text { Typic } \\
\text { Troporthents }\end{array}$ & TT-L & 5885 & 0,58 & 4 & 5 & 0,730 & $\begin{array}{l}\text { sangat } \\
\text { tinggi }\end{array}$ \\
\hline 9 & $\begin{array}{l}\text { Typic } \\
\text { Troporthents }\end{array}$ & $\begin{array}{l}\text { TT- } \\
\text { AC }\end{array}$ & 4608 & 0,57 & 4 & 5 & 0,580 & $\begin{array}{c}\text { Sangat } \\
\text { tinggi }\end{array}$ \\
\hline 10 & Lithic Haplustols & LH-D & 2434 & 2,06 & 3 & 5 & 0,278 & sedang \\
\hline 11 & Lithic Haplustols & LH-L & 3161 & 1,58 & 3 & 5 & 0,359 & agak tinggi \\
\hline 12 & Lithic Haplustols & $\begin{array}{l}\text { LH- } \\
\mathrm{AC}\end{array}$ & 3482 & 0,55 & 3 & 5 & 0,421 & agak tingg \\
\hline
\end{tabular}

Keterangan: AC: Curam. D:Datar. L: Landai. LH: Lithic Haplustols. Pmb: Permeabilitas. TE:Typic Eutropepts. TH: Typic Hapluderts. TT: Typic Troporthents

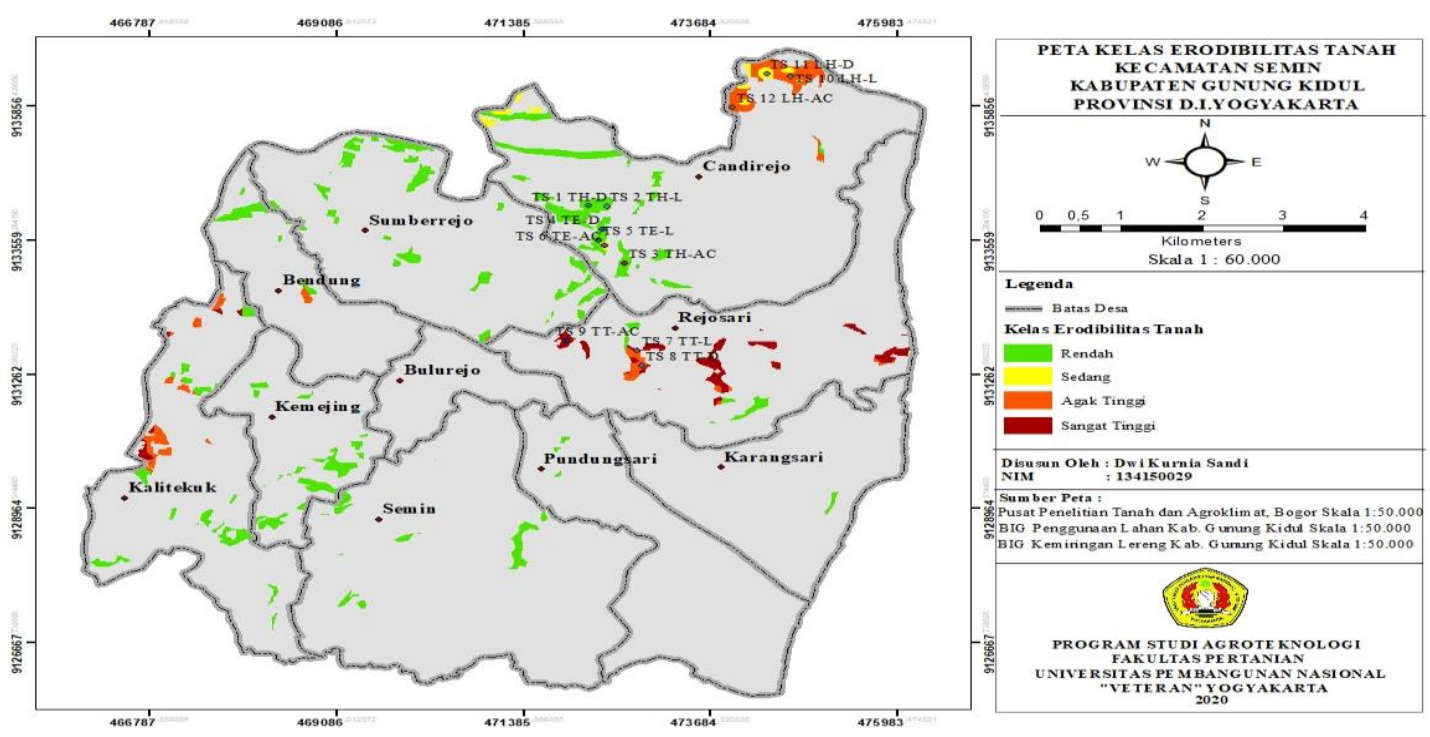

Gambar 1. Peta Kelas Erodibilitas Tanah Kecamatan Semin 
Pada sub group tanah yang sama dan kemiringan lereng berbeda diketahui bahwa nilai $\mathrm{K}$ tertinggi pada sub group tanah Typic Troporthents dengan kemiringan lereng landai, kemudian diikuti dengan kemiringan lereng agak curam dan yang terendah pada kemiringan lereng datar. Hal ini dikarenakan pada sub group tanah Typic Troporthents dengan kemiringan lereng landai, didominasi oleh fraksi pasir sangat halus dan debu, yang mana kedua fraksi tersebut tidak memiliki muatan sehingga lebih peka terhadap erosi, selain itu fraksi lempung yang lebih sedikit dibandingkan dengan Typic Troporthents Datar maupun Typic Troporthents Agak Curam.

Pada sub group tanah yang sama dan kemiringan lereng berbeda diketahui bahwa nilai K tertinggi pada sub group tanah Lithic Haplustols dengan kemiringan lereng agak curam, kemudian diikuti dengan kemiringan lereng landai dan yang terendah pada kemiringan lereng datar. Hal ini dikarenakan pada sub group tanah Lithic Haplustols dengan kemiringan lereng agak curam, didominasi oleh fraksi debu dan pasir sangat halus dibandingkan dengan fraksi lempung serta kandungan bahan organik yang sangat rendah sehingga agregat tanah atau ikatan antar partikel tanah yang tidak terlalu kuat. Menurut Subagyono et al.,. (2004), tanah-tanah yang cukup mengandung bahan organik umumnya menyebabkan struktur tanah menjadi mantap sehingga tahan terhadap erosi.

Pada kemiringan lereng datar dan sub group tanah berbeda diketahui bahwa nilai K tertinggi pada sub group tanah Typic Troporthents, kemudian diikuti sub group tanah Lithic Haplustols, Typic Eutropepts dan yang terendah pada sub group tanah Typic Hapluderts. Pada kemiringan lereng datar kepekaan tanah terhadap erosi termasuk kelas rendah, sedang hingga agak tinggi. Hal ini dikarenakan pada kelas kemiringan lereng datar aliran air permukaan lambat yang menyebabkan kesempatan air untuk terserap ke dalam tanah atau infiltrasi lebih tinggi dibandingkan dengan laju air permukaan. Sehingga partikel partikel tanah yang terbawa oleh aliran air permukaan lebih sedikit.

Pada kemiringan lereng landai dan sub group tanah berbeda diketahui bahwa nilai $\mathrm{K}$ tertinggi pada sub group tanah Typic Troporthents, kemudian diikuti sub group tanah Lithic Haplustols, Typic Eutropepts dan yang terendah pada sub group tanah Typic Hapluderts. Pada kemiringan lereng landai kepekaan tanah terhadap erosi termasuk kelas rendah, sedang, agak tinggi hingga sangat tinggi. Hal ini dikarenakan pada kelas kemiringan lereng landai aliran air permukaan lebih cepat dibandingkan dengan kemiringan lereng datar yang menyebabkan kesempatan air untuk terserap ke dalam tanah atau infiltrasi lebih rendah dibandingkan dengan laju air permukaan.

Pada kemiringan lereng agak curam dan sub group tanah berbeda, diketahui bahwa nilai K tertinggi pada sub group tanah Typic Troporthents, kemudian diikuti sub group tanah Lithic Haplustols, Typic Eutropepts dan yang terendah pada sub group tanah Typic Hapluderts. Pada kemiringan lereng agak curam memilik kepekaan tanah terhadap erosi bervariasi mulai dari kelas rendah, sedang, agak tinggi hingga sangat tinggi. Pada kemiringan lereng agak curam resiko untuk terjadinya erosi lebih tinggi karena kesempatan air untuk terserap ke dalam tanah atau infiltrasi lebih rendah dibandingkan dengan laju air permukaan, hal ini nantinya mempengaruhi laju erosi di suatu lahan. 


\section{KESIMPULAN}

Tingkat erodibilitas tanah di Kecamatan Semin berkisar dari rendah hingga sangat tinggi dengan nilai $0,184-0,730$. Semakin tinggi tingkat kelerengan, nilai erodibilitas cenderung semakin tinggi kecuali pada ordo vertisol yang relatif sama. Ordo Entisol mempunyai nilai erodibilitas tanah paling tinggi. Kelas erodibilitas sangat tinggi terdapat di Desa Rejosari, agak tinggi terdapat di Desa Candirejo dan Desa Rejosari, sedang terdapat di Desa Candirejo, dan kelas erodibilitas rendah terdapat di Desa Candirejo, Desa Kemejing dan Desa Sumberrejo. Satuan peta lahan yang mempunyai tingkat erodibilitas agak tinggi dan sangat tinggi adalah satuan lahan yang mempunyai kandungan bahan organik yang rendah dan yang mempunyai kandungan pasir sangat halus dan debu tinggi.

\section{DAFTAR PUSTAKA}

Bryan, R.B., Govers, G., Poesen, J., 1989. The concept of soil erodibility and some problems of assessment and application. Catena 16, 393-412.

De Ploey, J. and J. Poesen. 1985. Aggregate stability, runoff generation and Interrill erosion. pp. 99-120. In: K.S. Richards, R.R. Amett, and S. Ellis (eds.), Geomorphology and Soils. Allen and Unwin, London, England.

Dusan, Z., 1982. Soil Erosion. : Development in Soil Science, 10. Elsevier, Amsterdam.

PPTA. 2001. Peta Tanah Kecamatan Semin skala 1:50.000. Badan Pusat Penelitian Tanah dan Agroklimat: Bogor.

Soil Survey Staff. 2014. Kunci Taksonomi Tanah. Edisi Ketiga, 2014. Balai Besar Penelitian dan Pengembangan Sumberdaya Lahan Pertanian, Badan Penelitian dan Pengembangan Pertanian.

Subagyono, K. Ai Dariah, dan J.E. Surmain. 2004. Pengelolaan air pada tanah sawah. Puslitbangtanak. Bogor.

Wischmeier W. H, and Smith, D. 1978. Predicting Rainfall Erosion Losses, Agriculture Hand Book. No. 282. USDA: Washington DC.

Wang, B; F. Zheng; Mathias J.M. Römkens; F. Darboux. 2013. Soil erodibility for water erosion: A perspective and Chinese experiences. Geomorphology 187: $1-10$ 